\title{
Role of Gluten-free Foods in Celiac Disease
}

\author{
${ }^{1}$ Swapan K Paul, ${ }^{2}$ Amrita Ghosh, ${ }^{3}$ Ranabir Pal, ${ }^{4}$ Shrayan Pal
}

\section{ABSTRACT}

Background: Celiac disease is an autoimmune disease triggered by presence of gluten in food items, which precipitates specific symptoms of the disease.

Objectives: To find novel concepts on diets in celiac disease, we summarized information from literature sources which needs further translational researches.

Results: Though there are abundant literature on celiac disease about its etiology, signs and symptoms and diet models, there is no specific treatment and management protocol other than gluten-free food.

Conclusion: A sincere discourse on the critical issue of dietary advice in celiac disease is very much required for primary health care providers, to be conversant with clinical features and outcomes with alternate treatment modalities.

Keywords: Celiac disease, Compliance, Diet.

How to cite this article: Paul SK, Ghosh A, Pal R, Pal S. Role of Gluten-free Foods in Celiac Disease. Bengal Physician Journal 2018;5(3):40-41.

\section{Source of support: Nil}

Conflict of interest: None

\section{CELIAC DISEASE}

Celiac disease is autoimmune morbidity with the pathogenesis of inflammation in intestinal villi leading to inconsistent absorption and downstream malnutrition, triggered by gluten present in cereals like wheat, barley, rye, oats, etc. which are used in pieces of bread, pasta, pizza, cakes, pies, and cookies and many processed food items. Celiac disease is a reversible disease affecting about one percent of the population presenting with chronic diarrhea, fatigue, and weight loss. In delayed diagnosis or no diagnosis, with continued consumption of gluten, nutrient deficiency and co-morbidities viz. anemia from iron, folate and vitamin B12 deficiency, reduced bone

\footnotetext{
${ }^{1}$ Assistant Professor, ${ }^{2}$ Demonstrator, ${ }^{3}$ Professor ${ }^{4}$ Resident

1,3 Department of Community Medicine, MGM Medical College and LSK Hospital, Kishanganj, Bihar, India
}

${ }^{2}$ Department of Biochemistry, Medical College, Kolkata, West Bengal, India

${ }^{4}$ Department of Dermatology, Venereology and Leprosy, MGM Medical College and LSK Hospital, Kishanganj, Bihar, India

Corresponding Author: Amrita Ghosh, Demonstrator, Department of Biochemistry, Medical College, Kolkata, West Bengal, India e-mail: amritaghosh1973@yahoo.com density, continued weight loss, etc. ${ }^{1-3}$ Recent study from India reported celiac disease to be more common in northern India, (1.2\%) as compared to northeastern (0.8\%) and the southern part $(0.1 \%) .{ }^{4-7}$ Celiac disease usually presents with abdominal discomfort, diarrhea or constipation, bloating, weight loss, etc. and assorted micronutrient deficiencies including anemia; osteoporosis; diabetes; hypothyroidism; dermatitis herpetiformis; neurological and hepatic disorders. One in ten celiac disease cases continue symptoms in spite of adhering to the gluten-free diet, known as 'nonresponsive celiac disease' or 'refractory celiac disease'; may be due to malabsorption syndromes, allergies, intestinal microbial overgrowth, irritable bowel syndrome, colitis, rarely lymphoma. ${ }^{8,9}$

\section{Gluten-free Foods}

Planning of gluten-free food is a challenging task, though many naturally gluten-free foods are available including fruits and vegetables, meat and poultry, freshwater fish and seafood, dairy, legumes, and nuts; also there are gluten-free grains and starches like amaranth, rice, sago, sorghum, soya, tapioca, arrowroot, corn, flax, millet, potato, etc. ${ }^{10}$ though entity of 'non-celiac gluten sensitivity', 'gluten ataxia', 'wheat allergy' and fermentable oligo-, Di-, mono-saccharides and polyols (FODMAP) sensitivity is also observed mimicking celiac disease. ${ }^{11}$ Also, celiac disease management should include stress-free lifestyle with dietary options viz., high fiber, vitamin-and-mineralrich fruits, vegetables, naturally fermented probiotic items, along with the reduction of processed products, refined grains, sugars, which feeds bad bacteria and worsens dysbiosis. Research groups suggested the inclusion of herbs and spices like basil ginger, garlic, turmeric, thyme, cinnamon, etc. fish oil, walnuts, flax, and olive oil, tea, and bone broth, to reduce gut inflammation. ${ }^{12,13}$ Elimination of gluten from diet adversely affects overall intake of fiber, vitamins and other macro and micronutrients and may cause varied ill effects on health. Here comes usefulness of Paleo diet, which addresses co-existing non-celiac problems aggravating celiac disease symptoms with foods containing iron and vitamins from liver, meat, egg, shellfish; carotenoid and ascorbic acid from fruits and vegetables; vitamin $\mathrm{D}$ from fatty fresh-water fish; calcium from dark green leafy vegetables, bone-in fish, and dairy if the patient can tolerate it; all the above should be consumed with precaution with cooking and preparation to prevent biodegradation. ${ }^{14,15}$ Due to miscampaign by business 
houses, persons without celiac disease are also consuming gluten-free-foods to get perceived health benefits. Hence, it is necessary to provide riders not to consume this diet in persons without the celiac disease. Stakeholders should make holistic approach including physicians, nutritionists, dieticians, teachers to do a positive and intense campaign to raise consumer awareness and with enforcement of food standards and regulations along with government-level intervention. ${ }^{16}$ Of late, there is growing interest regarding the role of FODMAPs in celiac disease to improve symptoms by changing gut flora. ${ }^{17}$

\section{Take Home Message}

Celiac disease is permanent gluten intolerance, and the pathogenesis involves manifold factors including ending in the common gastrointestinal presentations. Till date, the most important intervention is the rigorous omission of gluten-containing dietary items and nutrient materials from the diet. This is done irrespective of qualitative and quantitative presence and absence of mild, moderate or severe gastrointestinal and other systemic morbidities to avoid exacerbation of clinical features originating from inflammation of the gastrointestinal mucosa leading to lymphoproliferative malignancies and immunological disorders. It is most unfortunate that by the exclusion of gluten from diet disturbs taste and satiety from derangement of portion and choices may become detrimental in nutritional supply for general metabolism. This may even lead to uneven consumption of all macronutrients and micronutrients from natural sources, which may result in clinical and subclinical deficiency features. Holistic dietary counseling of the celiac disease patients and their caregivers can only solve this impasse. The authors of this article feel that involvement of the family members to be ensured in decision making as empathetic motivation and support is important in case of celiac disease patients which is a lifelong chronic disease entity with the mainstay of treatment of dietary modification.

\section{REFERENCES}

1. Gluten-Free Diet Guide for Families. [online] [cited 21.12.2018] Retrieved from: https://www.gikids.org/files/documents/ resources/Gluten-FreeDietGuideWeb.pdf
2. What is coeliac disease? [online] [cited 02.11.2018] Retrieved from: https://www.schaer.com/en-ind/a/what-coeliac-disease

3. What's Gluten? [online] [cited 03.11.2018] Retrieved from: https://kidshealth.org/en/kids/celiac.html

4. 'One in 90 people in north India suffer from celiac disease'. [online] [cited 22.11.2018] Retrieved from: https://www. theweek.in/news/sci-tech/celiac-disease-north-india.html

5. 1 In 100 People in North India Suffer from Celiac Disease. [online] [cited 12.11.2018] Retrieved from: https://www. indiatimes.com/health/healthyliving/1-in-100-people-innorth-india-suffer-from-celiac-disease-329518.html

6. Gluten-free, not celiac friendly. [online] [cited 15.11.2018] Retrieved from: https://timesofindia.indiatimes.com/lifestyle/health-fitness/health-news/gluten-free-not-celiacfriendly/articleshow/56197739.cms

7. 6 to 8 Million Indians Suffer from Celiac Disease: Go GlutenFree to Manage the Condition. [online] [cited 19.11.2018] Retrieved from: https://www.ndtv.com/food/6-to-8-million-indians-suffer-from-celiac-disease-go-gluten-free-tomanage-the-condition-1748085

8. Patient education: Celiac disease in adults (Beyond the Basics) [online] [cited 02.11.2018] Retrieved from: https://www.uptodate.com/contents/celiac-disease-in-adults-beyond-the-basics

9. Symptoms of Celiac Disease.[online] [cited 02.11.2018] Retrieved from: https://celiac.org/about-celiac-disease/ symptoms-of-celiac-disease/

10. Gluten-Free Diet Guide for Families. [online] [cited 02.11.2018] Retrieved from: https://www.gikids.org/files/documents/ resources/Gluten-FreeDietGuideWeb.pdf

11. Is Non-Celiac Gluten Sensitivity a Real Thing? [online] [cited 02.11.2018] Retrieved from: https://www.healthline. com/health-news/is-non-celiac-gluten-sensitivity-a-realthing-041615\#11

12. Gluten-free diet. [online] [cited 02.11.2018] Retrieved from: https://www.mayoclinic.org/healthy-lifestyle/nutritionand-healthy-eating/in-depth/gluten-free-diet/art-20048530

13. Looking Beyond Gluten Free: Choose a Gut-Supportive Diet for Long-Term Health with Celiac Disease. [online] [cited 02.11.2018] Retrieved from: https://gluten.org/lookingbeyond-gluten-free-choose-gut-supportive-diet-long-termhealth-celiac-disease/

14. Paleo and Celiac Disease: It's More than Gluten. [online] [cited 02.11.2018] Retrieved from: https://paleoleap.com/ paleo-celiac-disease/

15. The Foods to Eat and Avoid if you're Going Gluten Free for Celiac Disease. [online] [cited 02.11.2018] Retrieved from: https://www.everydayhealth.com/celiac-disease/guide/diet/

16. Gluten-Free Diet: A Review Focusing on Wise Food Choices [online] [cited 02.11.2018] Retrieved from: https://www. ecronicon.com/ecnu/pdf/ECNU-13-00518.pdf

17. Taus M, Mignini EV, Fumelli D, Busni D, Nicolai G, Carletti C, et al. Celiac Disease: Gluten Free Diet and...What Else? Open J Gastroenterol 2016;6:157-170. 